\title{
Myeloid Maturation Index
}

National Cancer Institute

\section{Source}

National Cancer Institute. Myeloid Maturation Index. NCI Thesaurus. Code C135434.

The determination of the ratio of the sum of myeloid maturation phase cells (pool) to the sum of myeloid proliferative phase cells (pool) present in a sample. 